\title{
Abstracts of the 4th Pan American Regional Conference of WADEM
}

\author{
October 15-17, 2012 \\ Leesburg, Virginia USA
}

doi:10.1017/S1049023X13000253

Online publication: April 5, 2013

\section{S 1-O3 Psychosocial Papers and Discussions \\ October 15, 2012 10:30-5:30}

\author{
S1-03-01: New Strategies for Reducing Responder Risk: From Pre-Deployment Screening to Post-Deployment Support \\ Valerie Cole, American Red Cross (United States)
}

Background: This presentation will provide an overview of Red Cross strategies for reducing responder risk spanning the continuum of pre-deployment to post-deployment. The psychological literature describing the danger of compassion fatigue, burnout and secondary traumatization in disaster response is extensive. Volunteers in all areas, from phone operators to first responders, face unexpected stressors which can lead to brief periods of distress or, at worst, longlasting negative psychological consequences. A sampling of this literature will be presented, with special emphasis on international humanitarian response organizations.

Force Health Protection is important for several reasons, including the expense involved in recruiting and training new people, continuity of care, the resilience of the work force and protection of the volunteer's emotional health. The issue is one of appropriate sequencing: take care of the responder first and then disaster victims and survivors.

Methods: Strategies include: pre-deployment screening and mental health messaging; utilization of client mental health surveillance tools to monitor worker exposure; identification of worker risk factors and use of triage and psychological first aid techniques; post-deployment support, screening and mental health messaging.

Results: Participants should be able to 1) understand the need for force health protection strategies that mitigate responder stress; 2) recognize the risk factors associated with compassion fatigue, secondary traumatization and burnout in disaster settings; and 3) identify appropriate strategies to protect the volunteer.

Conclusions: There are significant challenges with the move ahead in this area. Disaster settings, leadership, and our organizations themselves can create barriers to promoting responder care. Yet, if it is chosen to do this important workhelp people during their times of greatest need-then it is incumbent on providers to do the best job possible-and that requires first protecting responders to ensure there are the tools

\section{S1-03-02: Effectiveness of Training Program on Psychosocial Disaster Preparedness for Children Among NGO Workers \\ Elangovan Aravind Raj, Kasturba Medical College (India); Kasi Sekar, NIMHANS (India); C Nambi, Center For Social Education E̋ Development (India)}

Non-governmental organizations (NGOs) play an important role in the implementation of disaster management programs in the community. Community Based Disaster Preparedness is strengthened through a combination of appropriate information technology and collaborative relationships between NGOs and community-based organizations (Troy, et al 2008). Among various aspects of preparedness, psychosocial disaster preparedness for children is one important dimension that is not focused adequately for various reasons. One among such reasons is the lack of training for the NGO personnel. With this background, the current paper attempts to find out the effectiveness of training program on psychosocial disaster preparedness for children (Raj, 2011) among NGO personnel.

NGOs in Tamil Nadu, India who have worked in disasters were contacted to send their personnel for the two day training program on psychosocial disaster preparedness for children. 25 personnel from 10 NGOs attended the training program. None of the participants had prior exposure to any training 
program in this area. The content of the program covered understanding of disasters, psychosocial consequences and psychosocial disaster preparedness at individual, family and community level. Base line assessment on knowledge about disaster management, disaster preparedness and psychosocial disaster preparedness were done before the training program and the effectiveness of the program was assessed using post assessment and qualitative feedback. The results revealed that their knowledge on psychosocial disaster preparedness in post assessment is significantly higher than the pre assessment $(\mathrm{t}=-13.4, \mathrm{df}=24, \mathrm{p}<0.001)$. The qualitative assessment also revealed that the participatory methodology used in the training program helped them to understand and internalize the content of the program in an effective way. The implication of the current study is that such training program would enable them to incorporate psychosocial disaster preparedness component while working with children that would reduce the psychosocial impact on children.

\section{S1-03-03: Capacity Building for Social Work Students on Psychosocial Care for Survivors of Disaster} Elangovan Aravind Raj, Kasturba Medical College (India); Gunasagari Rao, Dept of Psychiatry (India); Rajini Gopinath, Kasturba Medical
College (India); Elumalai Sinu, Kasturba Medical College (India)

Disasters usually leave a trail of human agony resulting in long-term psychosocial and mental health problems. Apart from logistic and material help, the affected community requires Psycho-Social Support and Mental Health Services (PSSMHS). The importance of mental health and psycho-social interventions after disasters has been increasingly recognized. The World Health Organization (WHO) recommends that appropriate interventions are necessary to prevent and manage the psycho-social and mental health consequences of a disaster (NDMA, 2009). But the growing inadequacy of the available human resources is evident and resources in PSSMHS are grossly inadequate to cater to the needs of our country. Social Workers being one of the main stakeholders in provision of psychosocial support and mental health services should be equipped with adequate knowledge and skills of the same during their post graduate program.

The current study details the effectiveness of the training program on psychosocial care in disaster management (Sekar,
2005) for post graduate social work students from different schools of social work in Udupi District, Karnataka, India. 25 students attended the three day training program. The content included reactions due to stress, techniques of psychosocial care, spectrum of care, various mediums to work with children, identifying the resources of women and stress management for care givers. Participatory methodology such as brain storming, group activities, role play was adopted. Quantitative and qualitative assessment tools were used to measure the outcome of the program. The pre and post assessment revealed a significant difference in their knowledge on provision of psychosocial care during disasters. The outcome of the training program reflects on the level of preparedness among the trained social workers. The findings would also help in suggesting the universities to include not only the content but also the participatory methodology while imparting education to the social work students.

\section{S1-03-04: Health Emergency Response for Vulnerable Persons: Learnings from Canterbury's Earthquake, NZ}

\section{Toni Gutschlag, Canterbury District Health Board (New Zealand); Becky Hickmott, Canterbury District Health Board (New Zealand)}

Background: A 7.1 earthquake hit the Canterbury region of New Zealand (NZ) on September 4, 2010. Aged and Residential Care (ARC) facilities sustained significant damage. The Canterbury District Health Board (CDHB) recognized that many people were not able to be supported through the general community response and set up a team to support vulnerable people. This Vulnerable Persons (VP) team assisted ARC services to keep operating and was a central contact point for welfare and social agencies. On February 2011 a 6.3 earthquake struck with 6659 injured, 185 deaths and severe infrastructure damage. Many ARC facilities were damaged and several destroyed, $600+$ ARC beds were lost, 500 residents required evacuation. The VP Team was re-established coordinating the evacuations, and supporting mental health community providers, disability providers, and the ARC sector to continue running 4,500 ARC beds with no water, power or sewage.

Methods: A helpline was established as a key point of contact for relatives seeking information about evacuees. Senior clinicians were deployed to undertake urgent assessment of residents and facilities to assist with care and determine whether evacuation was required. The team developed a system wide view of capacity and need across residential services.

Results: The VP Team brought together senior clinical leaders to provide extraordinary support to individuals and organizations which kept essential services open. Although the lens for acceptable care changed, services kept operating safely and vulnerable people were supported in their community.

Conclusions: The establishment of the VP team demonstrates CDHBs commitment to its community and to the safety and welfare of vulnerable people. It is now an established part of our emergency response.

Toni Gutschlag, Vulnerable People Team Leader/Planning \& Funding Team Leader toni.gutschlag@cdhb.govt.nz 064272127305

Becky Hickmott, Nurse Coordinator/Repatriation Team Leader 
S1-03-05: Systems Level Responsiveness and Management of the Needs of the Vulnerable People in Disaster: Learnings on the Social and Ethical Factors for the Vulnerable Pople of Canterbury, New Zealand, Post Seismic Events 2011-2012.

\author{
Becky Hickmott, Canterbury District Health Board (New Zealand); Toni Gutschlag, Canterbury District Health Board (New Zealand)
}

Background: A 7.1 earthquake hit the Canterbury region of New Zealand (NZ) on 4/9/2010. Some communities and various Aged and Residential Care (ARC) facilities sustained significant damage. The Canterbury District Health Board (CDHB) set up a team to work directly with this vulnerable population. On February 2011 a devastatingly shallow 6.3 earthquake struck with hundreds injured, loss of life and severe infrastructure damage. Many ARC facilities were badly damaged and several destroyed. Over 600 ARC beds were lost and 500 elderly and disabled people were displaced. In order to provide safe care for this vulnerable group 300 people had to be relocated to other parts of NZ. A shortage of ARC beds resulted within Canterbury with need for additional residential care admissions placing pressure on the sector. An expert panel was convened to develop ethical guidelines determining allocation of the ARC beds as well as to manage the repatriation of the evacuated elderly back into Canterbury. The panel comprised of older person health clinicians, general practice, aged care advocates and an ethicist.

Methods: Guidelines ensured individual assessments using set criteria and ranking processes for the clinical, social and compassionate needs of the person. A single point of entry system (SPOE) was established to control access to all beds. CDHB established a Repatriation Team to contact, visit and assess each of the evacuated people. Families and guardians were contacted to ascertain needs and wishes. A "Prioritization Decision Panel" was established to determine the individual's priority level outcome once the person was assessed.

Results: SPOE was successfully established and utilized across the ARC sector. The repatriation process enabled all surviving evacuated residents to be repatriated to Canterbury.

Conclusions: The responsiveness, capability and innovation demonstrated under crisis resulted in successful and ethical management under challenging circumstances.

\title{
S1-03-06: The Conjoint Community Resiliency Assessment Measure (CCRAM) Pilot Study
}

Limor Aharonson-Daniel, Ben-Gurion University of the Negev (Israel); Mooli Lahad, Tel-Hai College, CSPC-The International Stress Prevention Centre (Israel); Dima Leykin, CSPC-The International Stress Prevention Centre (Israel); Odeya Cohen, Ben-Gurion University of the Negev (Israel); Avishay Goldberg, Ben-Gurion University of the Negev (Israel)

Introduction: Community Resiliency is seemingly a comprehended topic yet it has not been associated with replication of results from scientifically accepted methods of measurement. The CCRAM is an innovative tool, recently developed as an instrument for decision makers to monitor and control the resiliency of the community they are accountable for.

Methods: Nine communities were surveyed using the CCRAM tool as a pilot for the instrument's ability to monitor community resilience. Factor analysis was followed by Pearson correlational analysis to examine association between CCRAM factors and other background variables. Analyses of Variance (ANOVA) were used to examine effects of nominal variables on community resilience and interaction effects.

Results: Participants included 886 adults from three types of community. The mean age was 45.28 (SD 15.40, range 18-86) years. Average duration of living in same community was 27.42 (SD 16.9, range 1-67) years. The analysis used 31 items from the assessment tool and yielded six factors explaining $63.86 \%$ of the total variance. The overall reliability of the CCRAM was found to be excellent $(?=.94)$. Women reported higher community resilience (Two-way ANOVA $\mathrm{F}(1,876)=4.62, \mathrm{p}<.05)$, as did individuals belonging to emergency response teams, $F(1$, $866)=6.53, p<.05)$, Controlling for age, years in the community, education and belonging to emergency team, community resilience was strongly and positively correlated with satisfaction with quality of life in the community, $\operatorname{pr}(798)=.63, \mathrm{p}<.001$, as indicated by partial correlational analysis. The instrument facilitated comparisons of resiliency profile between communities, identifying strengths and weakness in each community in terms of the factors identified.

Conclusions: Repeated periodical measurements will facilitate comparisons across time and place. The group encourages the broad use of the CCRAM tool that can be obtained from the authors.

\section{S1-03-07: Resilience Through Discourse in Emergency Planning}

\section{Paul Whitehead, University of British Columbia (Canada); Linda MacNutt, Providence Health Care (Canada)}

Background: Prior to the pandemic outbreak of H1N1 influenza in 2009, there was concern about how to provide psychosocial support during pandemic influenza for roughly 10,000 health care providers (HCPs) affiliated with Providence Health Care in Vancouver, BC. For this study, research design focused on allowing HCPs to identify the supports they needed to maintain their resilience during such a disaster. Several key themes relate to the psychosocial support of HCPs during any disaster, and highlight the importance of pre-incident discussions as part of emergency preparedness planning. 
Methods: Eight focus groups were conducted with a total of 52 individuals from acute, residential and community facilities, including nurses, administrators, support services, allied health and physicians. The focus groups included a detailed information package concerning pandemic influenza, anxiety measures before and after this information package and anxiety management training. Thematic analysis of discussion transcripts led to the identification of 6 key themes which were validated using member checks and expert review.

Results: Six themes outline the emotional strain, areas of greatest stress, tension between competing demands, leadership behaviors and the nature of psychosocial support that these HCPs identified as critical in maintaining their resilience during a pandemic.

Conclusion: These results are in keeping with other research in this area, and yet an aspect common to all these themes still needs to be highlighted as key in terms of developing trust, mutual support and teamwork for HCPs during disaster response. This aspect concerned the importance of engagement in planning for disaster response, both in order to provide input, and also to experience a sense of team emerge from the group discussion process. This unexpected outcome in this research provides an insight into how the process of emergency preparedness planning can be used to enhance the psychosocial support of team members for one another.

\section{S1-03-08: Improving Psycho-Social Preparedness in Disaster Management: Lived Experiences and Learnings of Psycho-Social Recovery from the Canterbury Earthquakes, New Zealand}

Rose Henderson, Canterbury District Health Board (New Zealand)

Background: Whilst there was a Co-ordinated Incident Management System in place for dealing with emergencies, when a 7.1 earthquake struck Canterbury on 04 September 2011, we were ill prepared for dealing with the community and social impacts of a natural disaster. A steep learning curve led to a response team being identified, briefed, resourced and deployed within hours. Just over 4 months later, the devastating 22 February quake hit Christchurch. With the September experience as a "dress rehearsal", it was possible to quickly mobilize a response, building on the previous processes and networks. Active participation, planning and service delivery across local and central government agencies resulted in a much improved response and a significantly raised profile for mental health, resilience and wellbeing as central to community recovery.

Methods: As the full impact of the continuing seismic activity unfolds, ongoing responses are evolved to meet the psycho-social needs. Building psycho-social capacity, capability at individual, organizational and community levels is central to strengthening resilience and preparedness. Based on the 2007 United Nations Inter Agency Standing Committee (IASC) intervention pyramid, a range of programs and interventions continue to be developed and delivered across the community, responding to the changing needs. Psychosocial impacts on all aspects of the recovery planning (social, built, natural and economic environments from the locally developed Integrated Recovery Planning guide) have been recognized as an integral component of the recovery process.

Results: Studies are being undertaken on the various interventions. Outcome measures have been identified and will be tracked over the coming months prior to final collation and analysis. Early indications suggest that providing a range of responses to meet the identified needs of differing groups builds resilience and enhances recovery.

Conclusion: Better prepared individuals, organizations and communities are directly linked to enhanced resilience and recovery.

\section{S1-03-09: The Christchurch Experience: A Nursing Perspective}

\section{Joy Lyneham, University of Newcastle (Australia); Heather Byrne, National Guard Hospital (Saudi Arabia)}

Background: Despite their world literally falling down around them during the earthquakes in Christchurch (New Zealand) nurses continued to work both in the immediate hours and days following the quakes. Why nurses continued to work despite the obvious risks has been explored; however the research has usually occurred when the disaster is over. In this research the researchers were able to interview nurses while the declaration of disaster was still in force but after the immediate risks were contained. The aims of this research were to give nurses a voice and explore their experience as it evolved. Issues such as why they continued the work, the changes made to their practice and how the link between their personal and professional experience became entwined.

Methods: A hermeneutic phenomenological approach was employed for this study. This was considered appropriate as little is known about this period of nursing practice as previous studies explored the experience in hindsight. Ethical approval from the two committees involved was gained within 7 days. This paper will concentrate on the first three major quakes (final round not yet analyzed).

Results: Sixteen interviews were initially conducted and this diminished after each quake the last round of interviews only four remained. The interviews were conducted either on site, at the hospital or in a place nominated by the participant- this was to support psychological safety. The notion of care (professional and personal) featured strongly, practice was continually modified according to conditions, and this was tempered with some concerning risk taking behaviors such as returning into buildings while the quake was occurring.

Conclusions: Care and caring for patients and family took precedence over personal caring. Living with constant uncertainty is problematic in that over time the consequences of nursing during a disaster are a combination of increasing fragility or resilience. 


\title{
S1-03-10: Military Nurses in Disaster Deployments: Challenge, Growth, and Lessons Learned
}

Susan Speraw, University of Tennessee College of Nursing (United States); Felecia Rivers, Womack Army Medical Center (United States)

Background: Military nurses are often disaster first responders, yet minimal published research has examined their perspectives on disaster missions. This study aimed to explore and illuminate military nurses' experiences during disaster deploymentsundertakings defined as non-combat missions outside of warfare, including humanitarian relief operations or response to largescale natural or human-made events and garner lessons learned. Methods: Twenty-three military nurses from across all branches and across the USA, volunteers recruited through purposive, snowballing techniques, participated in one-hour face-to-face interviews. Phenomenological methods guided interviews and qualitative analysis. Results: Five polar and one unitary theme emerged: Nature of War v. Nature of Disaster; Unknown v. Known; Prepared v. Making Do; Structure v. Chaos; Being Strong v. Emotionality; and Existential Growth. Deployments were to natural events, terrorism, accidents and disease outbreaks; ranging from one day to six months. Overall, nurses' accounts emphasized human relationships. They considered their experience and framed narratives against the contextual ground of Organized Military Culture. Nurses found combat training inadequate preparation for disaster response, with differences between combat and disaster in: nature of the enemy, chains of command, and constantly shifting protocols necessitated by disaster chaos. High stress burden resulted from challenges in working collaboratively with civilian responders, in culturally unfamiliar settings, beyond the typical scope of nursing, and without post-response debriefing. "Being Strong", a core military value, was difficult in the face of catastrophic suffering and loss. Mutual peer support aided coping. Participants perceived personal growth in compassion and self-awareness and fuller appreciation of the destructive power of disasters and their impact on lives.

Conclusions: Joint simulation exercises involving military (all ranks) and civilian responders such as DMAT and organizations such as Red Cross are needed.

S1-03-11: Health Liaison and Civil Defence Emergency Operation Centre: The Role of Health Workers in the EOC National Civil Defence Operation

\section{Becky Hickmott, Canterbury District Health Board (New Zealand); Janice Lavelle, Canterbury District Health Board (New Zealand)}

Background: On 4/9/2010 a 7.1 earthquake hit Canterbury, New Zealand (NZ) causing significant damage to communities and facilities. The Canterbury District Health Board (CDHB) which funds nearly all health and disability services set up an Emergency Operations Centre (EOC). An important communication link was identified as missing between the health teams, the Civil Defense (CD) Controller and welfare in the CD headquarters. A Health Liaison (HL) role was established as a conduit for vital information to ensure a coordinated response to health and psychosocial issues identified as the extent of the crisis emerged. On February 2011 a devastatingly shallow 6.3 earthquake struck with 6659 injured, 185 deaths and severe infrastructure damage to the city. The HL was expanded to a team and immediately re-established. The role focused on intelligence gathering, information sharing, referral, triage, and emergency supplies. High hospital admissions and difficulty accessing community medical care required 200 teams from welfare to be sent to triage the health and safety of building occupants and the health needs found were profound. Welfare teams had non-health backgrounds and limited triage ability and knowledge of the health sector.

Methods: A family needs assessment was utilized and the HL provided triage, referral and problem solving support. A dedicated phone line was established and the HL Team was present in the CD EOC for 16 hours a day. Strong relationships were formed with support agencies along with EOC members from $\mathrm{CD}$ and $\mathrm{CDHB}$ including student nurses and their lecturers who provided staffing for essential services.

Results: The HL role is recognized as an essential part of the emergency response ensuring a consistent face to face transmission of information between agencies along with health advice and referral.

Conclusions: The responsiveness, capability and innovation demonstrated in developing the HL role resulted in transmission of information between agencies along with health advice and referral.

\section{S1-05 Forensic Aspects of Humanitarian Care Free Papers October 15, 2012 10:30-12:00}

\author{
S1-05-01: Forensic Medical Aspects of Humanitarian Response \\ Joyce Williams, Stevenson University (United States)
}

Background: Preparing for a large scale earthquake, a public health emergency such as a pandemic influenza or any major disaster

stresses the health system and a community to its limits. Effective response to humanitarian events is a recognized action of disaster 
teams in effort to secure and support nations. Forensic specialists, as members of disaster teams, are trained and prepared to respond to the multiplicity of situations and take on their role in an efficient and effective manner. The tornado that devastated Joplin, Missouri, and the earthquakes that pounded New Zealand and Japan underscores how quickly disruption can change lives "in the blink of an eye." Discussion: This paper will introduce the respected role and competency of scientific medical and forensic professionals provide when responding to a mass casualty event. Throughout the disaster cycle expertise is needed when community assets become compromised. Regions overwhelmed by an event have limited support for casualty surge, displaced populations, violence prevention, care of human remains, disease transmission, and the mental health of victims, families or staff.

Conclusion: The complexity of a humanitarian crisis places a significant burden on health officials. Utilizing the services of trained and dedicated professionals with expertise in emergency principles, forensic processes, public health orientation and medical interventions enables capacity building, opportunities for a more effective response with positive outcomes.

\title{
S1-05-02: Interdisciplinary Response to a Mass Fatality Incident
}

\section{David Williams, University of Maryland (United States); Joyce Williams, Stevenson University (United States)}

Background: Scientific Identification of the remains of victims of a Mass Fatality Incident (MFI) requires a multi-disciplinary approach. This presentation will review the events surrounding the crash of United Flight 93 on September 11, 2001, near Shanksville, Pennsylvania, and how this multi-disciplinary approach was successful in the identification of the 44 passengers of that flight.

Methods: This will be a case presentation based on personal experience. We will describe the history of the flight, actions taken before the incident including training and competence of individuals and pre-positioning of equipment; communication issues between the incident and the deployment; and the actual deployment including security, logistics, and personnel concerns. Procedural issues will be explained for each of the worksites: the family assistance center, the crash site and the morgue including the protocols developed and for the identification process.
Partnerships were forged during this terrorist event as well as atypical resource allocation. A review of the cooperative industries rarely tapped will be acknowledged.

Results: The successful scientific identification of those aboard United Flight 93 could only have been made through an interdisciplinary effort.

Conclusion: Large, complex events require a constellation of experts from the scientific community with experts from representing the forensic science fields to maximize the potential outcome. This team of experts can only function at an optimal level under the leadership of a commander who effectively manages and provides the assets they will need to be effective. Incidents involving representatives from various levels of government and agencies within these levels can evolve into jurisdictional battles but the case presented demonstrates how strong leadership and highly motivated participants can overcome these obstacles.

\section{S1-05-03: The Ability of the Death Care Sector to Respond to Mass Fatality Disasters}

\begin{abstract}
Robyn Gershon, University of California, San Francisco (United States); Halley Riley, University of California, San Francisco (United States); Lori Magda, University of California, San Francisco (United States); Jacqueline Merrill, University of California, San Francisco (United States)
\end{abstract}

Background: Both man-made incidents and natural disasters may present extreme challenges to communities and governments in terms of managing mass fatalities under severely compromised conditions. The psychosocial impact of poor or suboptimal management of the deceased in a mass fatality event can adversely affect disaster response and recovery and undermine community resiliency. In the United States (U.S.), the National Response Framework (NRF) describes the structure for the U.S. federal response to a large-scale public health disaster. Federal organizations and entities are called in to provide support to local Offices of Medical Examiners and Coroners (ME/C), which have direct responsibility for incident management of mass deaths. The ME/ $\mathrm{C}$ can call upon local members of the death care sector, whose members represent funeral related industries. But the ability of the death care sector to provide assistance to the local $\mathrm{ME} / \mathrm{C}$ has never been ascertained. To address this, we recently conducted a national survey of representatives of the U. S. death care sector.
Methods: Anonymous, web-based, cross-sectional survey of a national funeral industry sample. Preparedness was characterized using descriptive statistics. Factors significantly associated with ability and willingness was identified using chi-squared bivariate analysis.

Results: Respondents $(\mathrm{N}=492)$ generally rated their organizational preparedness planning as suboptimal; only six of 13 essential preparedness (ability) checklist items were typically in place. In contrast, response intentions were uniformly high; more than $80 \%$ of respondents were willing to report to work, although high prevalence of secondary obligations might hinder this. Personal responsibility for caring for elderly, disabled, or chronically ill family members was associated with lack of ability to provide support during mass fatality events $(\mathrm{OR}=2.74 ; 95 \%$ $\mathrm{CI}=1.23-6.10 ; \mathrm{P}=.01$ ).

Conclusions: Preparedness strategies that address inter-organization, surge capacity, and personal responsibilities of responders are optimal. 


\title{
S1-06 Research Priorities Free Papers
}

\section{October 15, 2012 10:30-3:00}

\author{
S1-06-01: Head Injuries Following Historic Tornados-Alabama, April 2011 \\ David Sugerman, CDC Division of Unintentional Injury (United States); Thomas Niederkrotenthaler, CDC National Center \\ for Injury Prevention and Control (United States), Erin Parker, CDC National Center for Injury Prevention and Control \\ (United States), Fernando Ovalle, CDC National Center for Injury Prevention and Control (United States), Rebecca Noe, CDC \\ National Center for Environmental Health (United States), Jeneita Bell CDC National Center for Injury Prevention and Control \\ (United States), Likang Xu (CDC National Center for Injury Prevention and Control (United States), Melissa Morrison, CDC \\ Office of Public Health Preparedness and Response and Alabama Department of Public Health, Caitlin Mertzlufft, Agency for Toxic \\ Substances and Disease Registry (ATSDR), Division Of Toxicology And Human Health Sciences, Geospatial Research, Analysis And \\ Services Program
}

Background: On April 27, 2011 multiple devastating tornados struck Alabama resulting in 256 deaths and over 1,500 reported injuries.

Methods: The Alabama Department of Public Health and CDC performed a retrospective review of emergency department (ED) and inpatient records in 39 hospitals that treated one or more injured patients. Cases were defined as tornado victims $>17$ years of age seen April 27-30, 2011 with an International Classification of Diseases, 9th Revision, Clinical Modification (ICD-9-CM) injury code of 800.0-959.9. All ICD-9-CM codes were analyzed with ICDMAP-90 to classify injury region and severity. We conducted phone interviews with 98 (7\%) of all abstracted cases and 200 uninjured community controls who responded to recruitment PSAs. Results: After extremity injuries, head injury was the most frequent diagnosis, representing $425(31.2 \%)$ of all injured patients. Of these, 393 (92.5\%) were minor with an Abbreviated Injury Score (AIS) $<3$, while $32(7.5 \%)$ were severe, AIS $\geq 3$. Only $71(16.7 \%)$ sustained isolated head injury, while all others presented with additional non-head injuries. Among those with head injury, 147 (34.6\%) were admitted for $\geq 1$ day; with 40 (9.4\%) requiring intensive care unit admission. Ten head injured patients $(2.3 \%)$ died, representing $71.4 \%$ of all hospitalized tornado deaths. Only three were in a personal or community storm shelter. No injured cases and eight uninjured controls reported using a helmet.

Conclusions: Most injured tornado patients with head injuries seen at local hospitals had minor injuries treated in the ED. The public should be educated to seek shelter in a tornado safe room or storm shelter. Due to the high frequency of head injury, head protection should be stressed among persons unable to get to a tornado safe room.

\section{S1-06-02: Healthcare Access and Needs After a Disaster: Impact of the 2010 Pakistan Floods}

Thomas Kirsch, Johns Hopkins University (United States); Gabrielle Jacquet, Johns Hopkins University (United States); Aqsa Durrani, Johns Hopkins University (United States); Lauren Sauer, Johns Hopkins University (United States); Shannon Doocy, Johns Hopkins Bloomberg School of Public Health (United States)

Objective: To assess variables predicting access to health services among populations affected by the 2010 Pakistan floods.

Methods: Population proportional, randomized cluster sampling was employed in the survey design. Eighty clusters of 20 households in the general population were selected for the study. Heads of households were surveyed approximately 6 months after onset.

Results: $77.8 \%$ of households reported needing health services in the month after the floods. Household characteristics including rural residence location, large household size, and pre- and post- flood income were significantly associated with access to adequate healthcare after the disaster. Households with inadequate access to health care were more likely to have a death or injury in the household.

Conclusions: Inadequate healthcare access after the 2010 Pakistani floods was associated with rural residence location, suggesting that locating healthcare providers in rural areas may be difficult. Access to health services was also associated with postflood income level, suggesting health resources are not readily available to households suffering great income losses.

\section{S1-06-03: The Health Impacts of Drought: A Review of the Evidence}

Carla Stanke, Health Protection Agency (United Kingdom); Marko Kerac, Health Protection Agency (United Kingdom); Virginia Murray, Health Protection Agency (United Kingdom)

Background: The recent Intergovernmental Panel on Climate Change (IPCC) climate change projections indicate more extreme weather events, including longer and more intense droughts, in different regions of the world. Drought differs from 
other natural hazards in that its exact beginning and end are difficult to define, unlike, for example, a heat wave or flood. Drought is closely related to other natural hazards including heat waves and wildfires, the health impacts of which are better documented. Relatively few published studies document the impacts of drought on public health, thus this review provides a summary of the best available evidence of what is known about drought and its impacts on human health.

Methods: To understand the health impacts associated with drought, the Extreme Events and Health Protection section of the UK's Health Protection Agency undertook a comprehensive literature review of the global evidence on the wider health effects of drought. Results: Drought has been linked to a number of public health impacts. Categories of health impacts include effects on nutrition (including mortality, micronutrient malnutrition, and antinutrient consumption), air-borne and dust-related disease, water-related disease, vector-borne disease, mental health effects and other (including injury, wildfire, and effects on infrastructure). The health effects of drought on populations vary according to the context where the drought occurs. Baseline vulnerabilities and societal infrastructure are key; countries with more resources and more robust health, sanitation and community management systems have greater ability to mitigate any potential health impacts.

Conclusion: The available evidence suggests that drought can have detrimental and sometimes catastrophic effects on public health, largely dependent upon the existing infrastructure and resources available for mitigation. Much more high-quality research is needed to document the associated health effects which occur as a result of these complex natural hazards so that emergency planners and health care providers can better plan for future drought events around the world.

\section{S1-06-04: Children and Terror Casualties Receive Preference in ICU Admissions}

\section{Kobi Peleg, Tel-Aviv University (Israel); Dolev Eran, Tel Aviv University (Israel); Dolev Eran, Tel Aviv University (Israel); Rosenfeld} Michael, Tel Aviv University (Israel)

Background: Trauma casualties caused by terror-related events and children injured as a result of trauma may be given preference in hospital emergency departments (EDs) due to their perceived importance. We investigated whether there are differences in the treatment and hospitalization of terror-related casualties compared to other types of injury events and between children and adults injured in terror-related events.

Methods: Retrospective study of 121,608 trauma patients from the Israel Trauma Registry during the period of October 2000-December 2005. Of the 10 hospitals included in the registry, 6 were level I trauma centers and 4 were regional trauma centers. Patients who were hospitalized or died in the ED or were transferred between hospitals were included in the registry.
Results: All analyses were controlled for Injury Severity Score (ISS). All patients with ISS 1-24 terror casualties had the highest frequency of intensive care unit (ICU) admissions when compared with patients after road traffic accidents (RTA) and other trauma. Among patients with terror-related casualties, children were admitted to ICU disproportionally to the severity of their injury. Logistic regression adjusted for injury severity and trauma type showed that both terror casualties and children have a higher probability of being admitted to the ICU.

Conclusions: Injured children are admitted to ICU more often than other age groups. Also, terror-related casualties are more frequently admitted to the ICU compared to those from other types of injury events. These differences were not directly related to a higher proportion of severe injuries among the preferred groups.

\section{S1-06-05: Effectiveness of Hyperbaric Oxygen and Ozone Applications in Tissue Healing at Generated Soft Tissue} Trauma Model of Rats: an Experimental Study

Ali Osman Yildirim, GATA Medical Faculty, Dept. Of Emergency Medicine (Turkey); Mehmet Eryilmaz, Gata Dept. of EM (Turkey); Murat Eroglu, GATA Haydarpasa Dept. of EM (Turkey); Serkan Bilgic, Gata Dept. of EM (Turkey); Murat Durusu, Gata (Turkey); Amit Kaldirim, Gata (Turkey); Emrah Eyi, Gata (Turkey); Salim Kemal Tuncer, Gata (Turkey); Turgut Topal, Gata Fizyoloji Ad. (Turkey); Alent Kurt, Gata Patoloji Ad (Turkey); Serkan Dilmen, Elazgasker Hast (Turkey); Mubittin Serdar, Gata Biyokimya Ad. (Turkey)

Introduction: There are some trials about the effectiveness of hyperbaric oxygen therapy (HOT) and ozone therapy in the cases in which the pathophysiology is associated with the tissue ischemia. In this study we aimed to interpret the effectiveness of hyperbaric oxygen and ozone therapies in the experimental soft tissue trauma model.

Materials and methods: Soft tissue trauma was generated by dropping a weight of 500 grams to the thigh region from height of 45 centimeters after anesthesia. Subjects were randomized to the three main groups of HOT (21), ozone (21) and control (21). HOT (2 hours a day 2.5 ATM) and Ozone/oxygen mixture
$(0.7 \mathrm{~g} / \mathrm{Kg} /$ day $)$ was applied to the subjects. Subjects of the both groups were sacrificed on the 1 st, 3 th and the 7 th days by random selection after the blood and the tissue samples were obtained. LPO, SOD, GSH-Px, HIF-1 and iNOS levels in the blood samples and the levels of inflammation and edema in the tissue samples were compared between the two groups.

Results: Statistically significant reduction was found in the levels of INOS and LPO in HOT and ozone groups compared with the control group. The histopathological examination manifest that the inflammation was reduced in both the HOT and the ozone groups compared with the control group compatible with 
the findings above. A significant reduction in the inflammation was found in both the HOT and the ozone groups compared with the control group. Additionally significant decrease in the edema was observed in all three groups histopathologically.
Discussion and conclusion: Consequently this study showed that HOT and the ozone therapy has beneficial effects in soft tissue trauma treatment. There is not any obvious evidence that shows superiority of one another between these two groups.

\section{S1-06-06: Dialysate Recycling System for Peritoneal Dialysis}

\section{Ichiro Tamazawa, Chiba University (Japan); Takuro Ishii, Chiba University (Japan); Tatsuo Igarashi, Chiba University (Japan)}

Background: A new concept of dialysate recycling system for Peritoneal Dialysis (PD) was designed to serve in the disastrous situations. A catastrophe occurred in the Eastern part of Japan last year. In the disastrous situation, more than 12,000 of patients with chronic renal failure had evacuated from the area to continue dialysis. Since PD can be applied in such a situation without electric power or water supply, we tried to develop a new system for PD which minimizes the amount of dialysate.

Methods: We prepared a dialyzer columns filled with high molecular weight substances with high osmolality to filter low molecule weight substances, and concentrate and re-perfuse irrigant drained from the abdominal cavity. The albumen powder, dissolved with saline, was used as test sample of high molecular substances. A dialyzer filled with saline was used as control. Dialysate for PD was infused to the dialyzer via the inlet of inner lumen of hollow fibers. The volume of filtered dialysate was measured according to the concentration of albumen. Results: Dialysate was filtered through the hollow fibers to dialyzer column in accordance with the concentration of the albumen: the volume of filtered dialysate measured at 3.0, 475.5, 534.0 , and $1000 \mathrm{~mL}$ when concentration of albumen was set at $0.0,8.1,15.0,18.0$, and $20.0 \mathrm{~g} / \mathrm{dL}$, respectively. However, linear relationship between filtered dialysate and albumen concentration was not established clearly.

Conclusion: Colloid osmotic pressure can be applied to dialysis to remove low molecular weight substances to reduce dialysate required for PD by recycling dialysate. Further experiment is mandatory to control filtering performance of the dialyzing system.

\section{S1-06-07: EMS in Kenya: Paving the Way Forward}

\section{Michelle Siemens, Independent (United States)}

Background: Kenya is a country wrought with emergencies, both natural and man-made. Traffic accidents, perinatal conditions, and ischemic heart disease are among the top ten causes of death. Kenyan health initiatives should be directed towards decreasing morbidity and mortality associated with trauma and medical emergencies. Establishing a quality emergency medical services (EMS) system is vital to minimizing the magnitude of this problem.

Kenya doesn't have a coordinated EMS system, and stakeholders have yet to produce an operational framework to strengthen the existing system. In 1966, the infamous "White Paper" paved the way for the USA to implement a fully developed EMS system. Stakeholders in Kenya have identified the need for a similar document to bridge this gap in EMS development.

Methods: The proposed White Paper will be developed in three parts. 1) A comprehensive literature review of EMS in Kenya will be completed. Literature will be used to draw comparisons and recommendations based on the USA and South African EMS systems. 2) Meetings will be held with stakeholders to ensure group consensus. 3) An operational framework will be drafted incorporating evidence based information and stakeholder input, providing a roadmap to the development of EMS in Kenya.

Results: The result of this project will be the creation of an authoritative EMS report for Kenya. This document will present specific recommendations for development of EMS in Kenya, providing a comprehensive picture of the current state of the system and the necessary steps for progress.

Conclusion: Lack of a coordinated EMS system in Kenya contributes to unnecessarily high morbidity and mortality. The first step to solving Kenya's complex issues is to provide a comprehensive analysis of EMS in Kenya and recommendations moving forward. This foundational initiative will lead Kenya to become the second African nation with a developed EMS system.

\section{S1-06-08: Preparedness of Pharmaceutical Services for Disasters in Brazil: Federal Level and Municipalities}

Elaine Miranda, Universidade Federal Fluminense (Brazil); James Fitzgerald, Pan American Health Organization (United States); Claudia Osorio-de-Castro, Escola Nacional de Saúde Pública-Fundação Oswaldo Cruz (Brazil); Paula Sousa, Escola Nacional de Saúde Pública-Fundação Oswaldo Cruz (Brazil)

Background: In 2011 Brazil experienced the worst natural disaster in its history and in the first half of 2012 more than 200 municipalities in the country declared an emergency due to drought or rain. The entire health sector, including pharmaceu- tical services (PS) which are available free of charge in the Brazilian Health System (SUS), needs to be prepared for disasters. The objective of this work is to describe and analyze preparedness of PS for disasters in Brazil, focusing on case studies 
in the federal level of the health system and in municipalities recently affected by disasters.

Methods: Case studies with a cross sectional design. A logic model was developed with elements of external context to pharmaceutical services and those pertaining to the political and organizational context of PS in the country. This model included implementation and performance dimensions and gave rise to an indicator framework. Data collected in document sources and from interviews with key informants was analyzed, according to All-Hazards/Whole-Health concept proposed by the WHO. Results: PS for disasters in the federal level is heavily centered on the supply and distribution of a medicines kit, by the Ministry of
Health. In municipalities problems regarding implementation and performance and lack of coordination between PS and civil defense were the most common. Key-informants reaffirmed that actions related to PS in disasters are split between involved segments and did not recognize the need of established protocols for action.

Conclusion: Preparedness in the country is not based upon the All-Hazards/Whole-Health rationale: actions involved in PS are vertical—not comprehensive, and are not directed to identified hazards. Studying preparedness of PS in Brazilian municipalities will clarify issues, indicate possible intervention strategies and consequently contribute to disaster response.

\title{
S1-06-09: So Many Questions: Important Directions for Future Inquiry in Disaster Medicine and Mass Gathering Medicine
}

\begin{abstract}
Sheila Turris, University of British Columbia_School of Nursing (Canada); Adam Lund, University of British Columbia-Department of Emergency Medicine (Canada)
\end{abstract}

Background: Disaster medicine (DM) and mass gathering medicine/health (MGM) are emerging, related fields. Planning and participation in MGM events represents an opportunity for ongoing training of health care professionals, thereby building DM capacity nationally and internationally. However, when comparing the bodies of literature, there are important gaps that need to be addressed.

Methods: Literature synthesis.

Results: Within the literature for DM and MGM, there are recurring themes with regard to research priorities, including the need to: - develop further theory and conceptual modeling in both DM and MGM; - establish consensus with regard to terminology to promote shared understanding and uniform reporting; - advance DM and MGM research beyond case reports so that conclusions can be drawn about categories of events and their risk profiles - leverage case reports to shape future inquiry so that questions can be asked and answered. Shared terminology and conceptual definitions will allow comparisons to be made between reports; further theory development will support decisions around medical and logistical team composition and operations; advancement of statistical methods will support accurate reporting of results; and, use of technology in the field to support medical teams, the collection of data, and standardized reporting, will positively influence patient, provider and community outcomes. Various suggestions and potential solutions have been posited such as linking groups of researchers internationally in shared projects and dialogue. Further development and expansion of an international Event and Patient Registry (mass casualty incidents and mass gathering events) with a uniform minimum data set should be a research priority.

Conclusion: In order to support systematic inquiry and to further development the underlying science of both DM and MGM, several collaborative research opportunities must be explored. Consensus on research priorities by the $\mathrm{MG}$ and $\mathrm{DM}$ communities will permit synergy in advancing the science underlying the management of mass casualty incidents.

\section{S1-06-10: Ambulance Design in India - Ensuring Quality within Constraints}

Shakti Kumar Gupta, All India Institute of Medical Sciences (India); Angel Rajan Singh, All India Institute of Medical Sciences (India); S K Patnaik, All India Institute of Medical Sciences (India)

Background: This study aimed to review the quality \& safety Standards of the Indian Road Ambulances \& to develop the design of a state of the art indigenous Advance Life Support Ambulance suitable for use in Indian Terrain \& Conditions.

Methods: Initially a checklist was prepared by reviewing the various safety standards in vogue globally and a pilot was conducted to check their relevance in the Indian Scenario. Field visits were conducted across the country \& consultations were also held with various vehicle research institutes in India like ARAI (Automotive Research Association on India), CIRT, etc. Results: The following unique findings were observed with regards the various parameters of existing Ambulance Design: - Vehicular Design: A limited number of vehicles with appropriate dimensions like loading height, etc. were available. - Fabrication: Primarily hand molded FRP was being used for interior fabrication which was cracking in the vagaries of weather. Due to the absence of National Standards regarding Ambulance Design, the industry was wary of investing in ABS Tooling, etc. -Manifold: There were no safety norms and standards being followed regarding the Oxygen Manifold System and easily available off the shelf components like garden hose were being primarily used - Electrical Systems: The vehicle alternators were under-rated and supplementary power was being provided through batteries connected in parallels which was unsafe. -Medical Equipment: The concept of equipment suitable and tested for ambulatory use was totally missing and hospital grade equipment was commonly in use.

Conclusion: It was observed that for the Quality of Ambulances in India to improve, an enabling legislation defining the minimum national standards for Ambulances in India needs to be enacted. 


\title{
S1-09 Roles of Emergency, Military, Nursing, and Medicine in Disaster Health Free Papers
}

October 15, 2012 1:30-5:00

\author{
S1-09-01: Simple "Care \& Safe" Concept for Disaster Action Team-Lessons Learnt from Several Natural Disasters in Indonesia \\ Ali Haedar, Dept of Emergency Medicine, Saiful Anwar General Hospital (Indonesia); Retty Ratnawati, Faculty of Medicine, \\ University of Brawijaya (Indonesia)
}

Background: Disaster Action Team (DAT) is intended to ensure that trained physicians and nurses can respond rapidly in a disaster event, where DAT should provide immediate, identifiable emergency services to those affected by disaster. However in the reality, we encountered some issues with DAT, i.e., too many DAT posts without good coordination among them, DAT is used as the best media for political parties' promotion, DAT only provides basic health care not advance health facilities, and DAT volunteer become burden for the affected people. Our University of Brawijaya Indonesia has organized "Team for Emergency and Disaster" (TED) in performing emergency medical assistance as DAT.

Methods: In determining our disaster services program, we applied 4 steps of action which is called "to CARE \& to SAFE" (Coordination, prepARE equipment \& tools, plan the System, and Arrange the Facilities) during the earthquake in West Sumatra (2009), flash flood in West Papua (2010), and volcano eruption in Central Java (2010). Each of these steps was in line with the disaster medical care concept of "to do the greatest good for the greatest number of patients".

Results: Our program concept had been applicable in 3 different types of disaster, either in advanced medical service post or basic medical service post. We have performed our emergency medical assistance by conducting a disaster assessment, assisting in opening a shelter and participates in mass feeding services, initiating interviews with those affected by the disaster to determine emergency needs, providing disaster health services, empowering local capacities, and completing any necessary reports or documents. We successfully carried on the established system and maintained system sustainability. Conclusion: Preparedness is essential to set up our DAT mission during the disaster. Performing good daily emergency practice in emergency department is the best learning method to manage a good disaster care.

\section{S1-09-02: Status of Trauma Care \& Disaster Preparedness in Delhi, India}

Angel Rajan Singh, All India Institute of Medical Sciences (India); Shakti Kumar Gupta, All India Institute of Medical Sciences (India); M C Misra, All India Institute of Medical Sciences (India); Sanjay Kumar Arya, All India Institute of Medical Sciences (India); Aarti Vij, All India Institute of Medical Sciences (India)

Background: Delhi, the Capital of India had the highest Accidental Death Rate of 45.3 per one lakh population amongst the metropolitan cities of India. In Delhi, the Directorate of Health Services is the major agency committed to delivery of health care while the pre-hospital care is provided by the Centralized Accident \& Trauma Services (CATS).

Methodology: This study was done to review the status of Trauma Care \& Disaster Preparedness in Delhi as of May 2010. Evaluation of the existing System in Delhi was done as per the Benchmarks Indicators Scoring tool contained in the United States Health Resources and Services Administration's "Model Trauma System Planning and Evaluation" guidelines. Scoring of various indictors was done on a progress scale of $0-5$, with $0=$ Not Known, $1=$ No Progress, $2=$ Minimal Progress, $3=$ Limited Progress, $4=$ Substantial Progress and $5=$ Full Progress.
Results: Of the 24 Benchmarks \& 113 Indicators reviewed under three broad functions, Delhi scored a median score of 1 in 'Assessment', 1.5 in 'Policy Development' \& 1 in 'Assurance'. Disaster Response was found to be organized and planned on paper. Key findings include multiplicity of command \& control, lack of a policy framework \& MIS, inadequate \& ill-equipped pre-hospital care, adequacy of funds, missing linkages between the Public Health System and the Emergency Response System. Conclusion: As evident from the scores, the existing system in Delhi has made no or very minimal progress. The components which are in existence are also not found to be functional optimally and there is no co-ordination amongst various agencies. Recommendations include the framing of an enabling legislation, development of a Trauma Plan/Standards of Care, Facility Designation, Capacity Enhancement, and Tabletop Drills. 


\section{S1-09-03: Review of the Role of Acute Care Facilities in Disaster Management in Delhi, India}

Angel Rajan Singh, All India Institute of Medical Sciences (India); Shakti Kumar Gupta, All India Institute of Medical Sciences (India)

Background: Acute care facilities in the NCT of Delhi are under the administrative control various bodies by way of the Delhi Govt., MCD, NDMC, Central Govt., Autonomous Institutions, Private Hospitals, etc. This presents a unique challenge to integrate them all into the State Disaster Plan.

Methodology: A record based review of the Acute Care Facilities across the State of Delhi was conducted to evaluate their roles in Disaster Scenarios. Field visits \& structured interviews with the end users were conducted to evaluate the real scenario vis a vis the recorded versions.

Results: Cutting across the administrative control limitations, there are a total of 30849 hospital beds available across the NCT of Delhi spread over an area of $1,483 \mathrm{sq}$. $\mathrm{km}$ for a total population of 13,850,507 which translates into approx. 22 beds for 10,000 population. This is above the national average of 7 beds per
10,000 population but below the global average of 25 beds per 10,000 population. The distribution of these beds across the nine districts of the state is not uniform with the Central District having 107 Beds/10,000 population vis a vis the North East District which has just 11 beds/10000 population. Further, there is little co-ordination between these facilities with regards to patient care, transfer $\&$ rehabilitation and no facility designation process is in place to map the level of care offered by each facility. Conclusions: In Delhi, multiplicity of Command \& Control hampers the integration of Acute Care Facilities in the state disaster plan. Though on paper, the facilities are designated as nodal response centers for their respective regions, lack of authority and action plan do not let it translate into action. The skewed bed distribution across the state presents a unique challenge in providing acute care and so does that lack of a legislative framework.

\section{S1-09-04: LSSD Dilemma: Hospital or Pre-hospital Services}

\section{Efraim Laor, Homeland Security Academy (Israel)}

Background: Large-scale sudden disasters (LSSDs), both natural and technological, are low probability high impact events that inflict injury or relocation upon hundreds of thousands or even several millions of people per incident. Many of the affected require medical — physical and mental — treatment. A 'Hospital' is traditionally a hub where the real medical treatment is administered. Community-care clinics and ambulance services, nicknamed 'pre-hospital', tasked to provide prompt life-support, stabilization then 'scoop \& run' to a hospital where the genuine curing would be granted to be released ASAP to 'post-hospital', recovery care (in LSSD?!?!) Research and personal observation in Disaster Areas demonstrate that in contrast to ever-ready operational capacity which corresponds to daily emergencies, there is an unbridgeable gap between standing-ops-capabilities and what is essential to be done due LSSDs to save lives and reduce damage to peoples' health. Hospitals are extremely resourceful during the preparedness phase, but ineffective to cope with masses of patients during the response phase. Therefore, it is imperative to call for a shift of duties. Hospitals should extend their proficiency, ethics, personnel, materiel and premises to what is labeled today "pre-hospital" activities: mobile clinics, primary care, but primarily enhance the participation of every individual, group and community in the emergency process by improving the methods of coping with perilous circumstances within the family unit and the community mechanisms. They must also train their staff for simple protocols and simplified outdoor treatment procedures during the response-phase. Hospitals should contribute to trim down Criteria \& Standards for the Level of Medical Treatment, one of the realistic methods to augment operational capacity. Hospitals are the sole organizations capable of granting professional legitimacy to such a move. Conclusion: LSSD circumstances, specifically NATECH, create dilemmas that crush traditional 'proved' paradigms and force endorsement of paradigms.

\section{S1-09-05: Field Hospital Activity Following an Earthquake}

Elhanan Bar-On, Schneider Children's Medical Center, Israel Defense Forces Medical Corps, Tel Aviv University-Sackler Medical School (Israel); Avi Abargel, Israel Defense Forces Home Front Command (Israel); Kobi Peleg, Department of Disaster Management School of Public Health Tel - Aviv University (Israel); Yitshak Kreiss, Israel Defense Forces Medical Corps (Israel)

Background: The Israel Defense Forces Medical Corps has deployed four acute phase field hospitals following major earthquakes: Armenia (1988), Turkey (1999), India (2001) and Haiti (2010). Significant differences were found in the amount and type of activity carried out in these four hospitals. The goals of the study were: 1 . To quantify and compare the activities carried out in the four hospitals. 2. To analyze factors affecting these activities. 3. To assess if the hospital activity and subsequent requirements can be anticipated at the stage of mission preparation. 4. To propose guidelines for future deployment of field hospitals in earthquake stricken zones. 
Methods: Quantitative data was collected from IDF records. Qualitative information was obtained by a structured interview with all mission commanders, IDF Surgeon Generals and additional key figures involved in the deployments.

Results: The hospitals were operational between 89 hours (Haiti) and 262 hours (Armenia) after the earthquake. All four hospitals were operational for 10 days. The number of patients treated varied greatly from 1,111 (Haiti) to 2,400 (Armenia) with wide differences in patient demographics regarding age, proportion of earthquake related diagnoses (28\%-66\%), and the number of surgical procedures performed (20-265). The variables affecting the type, quantity and severity of pathologies included:
Distance from the epicenter; Total number of injured; Time till deployment and Availability of evacuation destinations. Most of this information was unavailable during the early deployment stage.

Conclusions: Despite characteristic injury patterns following earthquakes, treatment capability requirements may vary widely between earthquake disaster zones. Customization is difficult in the first days following the earthquake due to the paucity of information. Field hospitals deployed in the early acute phase following an earthquake should have a wide range of acute care capabilities with the ability to adapt to the pathologies encountered.

\section{S1-09-06: Medical Relief Following Earthquakes: It's Time for a New Paradigm}

Kobi Peleg, Tel-Aviv University (Israel); Arthur Kellermann, RAND Corp (United States); Arthur Kellermann, RAND Corp (United States)

Global-scale disasters, such as the Haiti earthquake, generate huge numbers of casualties and simultaneously damage local infrastructure, including medical facilities. In such cases, the mix of resources sent to the scene by the international community may determine how many lives can be saved. Unfortunately, there is no internationally sanctioned after-action process to enable national disaster relief agencies and large nongovernmental organizations to learn from their experiences so that the next global response is more efficient and effective than the last. For example, data from 6 recent earthquakes suggest that the tradition of dispatching large numbers of urban search and rescue teams provides scant benefit relative to the substantial resources involved. Sending fewer urban search and rescue teams and more medical teams might save more lives. To ensure that the next response is more effective than the last, the major organizations that participate in each global disaster should convene under the auspices of the United Nations Disaster Advisory Committee (UNDAC) or the U.N.'s Office of Civil and Humanitarian Assistance (OCHA) to share their experiences, offer insights, and critique their response in a candid and non-judgmental way. Each meeting should produce an official "After Action Report" (AAR) that address, at a minimum, how the host country's needs were ascertained, the impact of decisions regarding what personnel, equipment and supplies were sent, how arriving teams and resources were staged, how transportation and security were arranged, and how various groups interacted with the host country, the local population, and each other. Creating and institutionalizing this process may be difficult at first, due to national pride and political sensitivities but it is essential to build a solid base of evidence to improve future responses.

\section{S1-09-07: Hematology and Oncology Doctors' Role in Mass Casualty Incident Preparedness}

\section{Cullen Case Jr, National Marrow Donor Program (United States)}

There are several mechanisms that could result in mass casualties with marrow toxic injuries that would involve the Hematology and Oncology departments at local cancer treatment centers; including exposure to ionizing radiation or to chemicals such as mustard agent. Every day, hematologists and oncologists treat cancer patients with symptoms similar to those of casualties with Acute Radiation Syndrome.

However, historic emergency preparedness involvement of these critical assets has been limited to the annual hospital fire or tornado drill. In response to an ionizing radiation incident Hematologists and Oncologists nationwide will be called upon to help treat the resulting surge of thousands of casualties. The Radiation Injury Treatment Network is a group of cancer treatment centers that have worked since 2006 to prepare to receive and treat casualties from such a disaster.

RITN centers have incorporated standard operating procedures, ARS treatment guidelines, annual training of staff from self- paced Basic Radiation Training to a Medical Grand Rounds, as well as conducting an annual tabletop exercise with institution, local and regional entities.

RITN serves as a model for increasing national preparedness for specialty care necessary in response to a national crisis.

\section{S1-09-08: Are Injuries from Terror and War Similar? A Comparison Study of Civilians and Soldiers}

\section{Kobi Peleg, Tel-Aviv University (Israel)}

Objective: To compare injuries and hospital utilization and outcomes from terror and war for civilians and soldiers.
Summary Background Data: Injuries from terror and war are not necessarily comparable, especially among civilians and soldiers. 
For example, civilians have less direct exposure to conflict and are unprepared for injury, whereas soldiers are psychologically and physically prepared for combat on battlefields that are often far from trauma centers. Evidence-based studies distinguishing and characterizing differences in injuries according to conflict type and population group are lacking.

Methods: A retrospective study was performed using hospitalization data from the Israel National Trauma Registry (10/2000-12/ 2006).

Results: Terror and war accounted for trauma hospitalizations among 1784 civilians and 802 soldiers. Most civilians (93\%) were injured in terror and transferred to trauma centers by land, whereas soldiers were transferred by land and air. Critical injuries and injuries to multiple body regions were more likely in terror than war. Soldiers tended to present with less severe injuries from war than from terror. Rates of first admission to orthopedic surgery were greater for all casualties with the exception of civilians injured in terror who were equally likely to be admitted to the intensive care unit. In-hospital mortality was higher among terror $(7 \%)$ than war $(2 \%)$ casualties, and particularly among civilians.

Conclusions: This study provides evidence that substantial differences exist in injury characteristics and hospital resources required to treat civilians and soldiers injured in terror and war. Hospital preparedness and management should focus on treating combat injuries that result from specific causes-terror or war.

\title{
S1-10 Introduction to Disaster Health Terminology October 15, 2012 3:30-4:15
}

\author{
S1-10-01: Using a Health Informatics Approach and Domain Ontology to Establish Disaster Health Terminology \\ Lidia Mayner, Flinders University (Australia); Paul Arbon, Flinders University (Australia); Pari Delir Haghighi, Monash University \\ (Australia); Frada Burstein, Monash University (Australia)
}

Background: The impact of disaster is increasing world-wide. To prepare for and respond adequately to these devastating events the science underpinning our disaster knowledge and practice must be improved. A lack of consensus on terminology and our inability to compare data in research reports is holding back progress on building this science. Many glossaries of terms exist and continue to be produced in texts and guidelines. The aim of this study is to produce a unified disaster health terminology using an approach commonly employed in health informatics.

Methods: Over 60 different glossaries relating to disaster health were analyzed. Leximancer was used to analyze the descriptions and relationships between the terms and Protége for representation of the domain ontology. Information was used from existing glossaries including the National Library of Medicine, USA. Each term was coded as the concept and the whole set of terms combined to form a disaster health domain ontology. In this paper results on three key terms, hazard, event and disaster, which are part of the Utstein conceptual framework for disasters, are presented.

Results: For the terms hazard and disaster over 30 different descriptions were found. Leximancer computed terms cause, property, natural, event and human as having highest relevance (90\% or above) to the term hazard and for disaster it computed affected, society, disruption, environmental, human, community and resources (all above $80 \%$ relevance).

Conclusion: This is a scientific and analytical approach to identifying existing consensus on the definition of disaster terms. Using domain ontology as a conceptual framework with text analysis software, allowed consensus knowledge to be identified and provide a unified definition of each term and corresponding description. This process is important because terms drawn from current literature and policy contain concepts most likely to be accepted by scientists and policy makers in a unified definition.

\section{S2-04 Psychosocial Papers and Discussions October 16, 2012 9:40-11:15}

\section{S2-04-01: Lessons from Social Media Messages Following 2010 Haiti Earthquake: Implications for Responder Preparation \& Practice}

Susan Speraw, University of Tennessee College of Nursing (United States); Maureen Baksh-Griffin, University of Tennessee College of Nursing (United States); Suzanne Boswell, University of Tennessee College of Nursing (United States)

Background: Social media communications following disaster have been used instrumentally to direct allocation of resources. No reports indicate that content has been used to qualitatively understand the human ordeal of living through disaster, shape responders' mental health preparation or practice in the field. This research addresses gaps with purposes: 1) to gather firstperson, real-time accounts of living through catastrophic disaster, for Haitian survivors and responders on the scene within the first 
days or weeks, and 2) analyze findings with an eye to maximizing intervention.

Methods: Human Subjects Review determined data usable: usergenerated-and-posted in the public domain for express purposes of dissemination. Thus, 3,602 Twitter messages generated onscene, 627 blog entries, and 176 notes on a Haiti listserv-all in English and posted from locations in Haiti to public social networking sites between January 12 and February 25, 2010were analyzed by researchers working together using content analysis and phenomenological methods. Line-by-line analysis of messages yielded a structure of recurrent themes.

Results: Social media message character limits forced authors to focus on core experience. Findings were surprising: responders and survivors wrote most about emotional, spiritual, existential concerns (death, isolation, meaning) and least about instrumental details (location, need for rescue). Responders were unprepared for their own strong emotional reactions, and did not report psychological interventions or survivors' existential struggles.

Conclusions: Responders have strong psychological reactions to disaster; current preparation was insufficient to mitigate those feelings. To function optimally in meeting survivor needs, preparation must include intensive training in psychological self-care, response and intervention. Trained responders with knowledge and skill in emotional caregiving who can avoid mental health trauma are likely freer to use inner resources to assist survivors struggling emotionally. Refined, data-based essentials for mental health training content will be suggested.

\section{S2-04-02: Psychosocial Dimensions of Widespread Population Exposure to Violence in Colombia}

James M. Shultz (US), Zelde Espinel (US/Colombia), Roberto Chaskel (Colombia), Carolina Ramirez (Colombia), Yuval Neria (US/Israel)

Background: The nation of Colombia provides a laboratory for examination and intervention on widespread population exposure to community and structural violence in the context of armed conflict. Of particular interest are the psychosocial aspects of high-prevalence, high-frequency exposure to violence.

Methods: This presentation will overview what is known about violence exposure in Colombia and describe an evolving research agenda for evidence-based research, training, and treatment.

Results: Armed conflict, dating from the period known as "La Violencia" in 1948, has resulted in at least 200,000 deaths. Over this 60-year period, a proliferation of armed actors including guerrilla (Las FARC, ELN) and paramilitary (AUC) have seized power in rural communities and impoverished urban neighborhoods, creating a checkerboard of control. Colombian citizens have endured extortion from competing militants, displacement, disappearance, kidnappings, assassinations, massacres, and forced recruitment of child soldiers into armed groups. Colombia has the highest number of internally displaced persons (IDPs) of any nation (3.6-5.2 million), including 96\% of IDPs in the Western Hemisphere. During the 1980s/1990s powerful drug cartels conducted a reign of terror; victims of Pablo Escobar's ruthless Medellin Cartel are estimated at 15,000. As the cartels were dismantled, the lucrative drug trade became more diffusely controlled by a combination of guerrilla, paramilitary, mafia, and common criminals. By providing the economic engine for these warring factions, drugs have played both direct and indirect roles in decades of human rights violations. Combinations of armed groups carried out extortive kidnappings of more than 15,000 victims and political kidnappings of Police, military, and government officials. The drug trade has recently diversified to trafficking both cocaine and heroin.

Conclusions: The majority of Colombians have witnessed or personally experienced a variety of potentially-traumatizing events. Most families have at least one direct victim of armed conflict and collectively, Colombia has experienced pervasive historical trauma.

\section{S2-09 Safe Medical Facilities Free Papers October 16, 2012 2:00-3:45}

\section{S2-09-01: A Methodological Approach for the Evaluation of Preparedness of Pharmaceutical Services \\ Elaine Miranda, Universidade Federal Fluminense (Brazil); James Fitzgerald, Pan American Health Organization (United States); Claudia Osorio-de-Castro, Escola Nacional de Saúde Pública-Fundação Oswaldo Cruz (Brazil)}

Background: Because Pharmaceutical Services are one of the crucial elements in the provision of disaster response, evaluating pharmaceutical services preparedness may contribute to access vulnerabilities of the medicines supply chain and to improve the quality and utility of health sector response. The aim of this work is to provide an outcome evaluation model of pharmaceutical services preparedness for disasters.
Methods: The development of the evaluation model was conducted in five steps. The first was a search of the literature, followed by the description of political and technical aspects, external context, implementation and performance of pharmaceutical services in disaster preparedness. After that a theoretical model on preparedness of pharmaceutical services in disasters was developed; the fourth step produced a comprehensive theoretical 
model for evaluation of preparedness of pharmaceutical services, uniting steps two and three; the fifth and final step contemplated the development of the indicator framework.

Results: For the development of this conceptual framework, and in light of the literature, we viewed PS as a program, which may be evaluated by measurable effects. External context was translated into three main aspects: resources and infrastructure, vulnerabilities and resilience. These elements of the model were also included when the indicators were formulated. The literature also subsidized the indicator framework. Each indicator was defined according to a series of published evaluation studies. The indicators that stemmed from the model had been previously validated in the literature in regard to exactly the same component that was used in the logic model

Conclusion: Health systems are increasingly obliged to be prepared for disasters. Therefore, a structured methodology to evaluate preparedness is a very useful tool. This conceptual approach is context-modulated and is deemed applicable in those that adopt the logistic cycle as the rationale for PS.

\section{S2-09-02: Development and Utilization of a Synchronization Matrix to Inform Better Response Decisions During Severe Weather}

Richard Smith, Yale New Haven Health System Center for Emergency Preparedness and Disaster Response (United States); Jeffrey
Schlegelmilch, Yale New Haven Health System Center for Emergency Preparedness and Disaster Response (United States); Joseph Albanese,
Yale new Haven Health System (United States); James Paturas, Center for Emergency Preparedness and Disaster Response (United States)

Background: During the preparation for impending emergencies or mitigation of disasters, Hospital Emergency Operations Centers (HEOC) are inundated with voluminous amounts of information related to the event. Incoming information necessitates confirmation, analysis and evaluation to inform decisionmaking affecting response operations. Here, we describe the development and utilization of a synchronization matrix (sync matrix), a tool for presenting structured information, during Hurricane Earl and Tropical Storm Irene.

Methods: The preparation of the sync matrix used strategies for structuring information described in best practice and planning documents. Rudimentary data were (re-)evaluated and important information was presented to HEOC staff at 12-24-hours intervals, prior to the landfalls of Hurricane Earl and Tropical Storm Irene, to identify key response decisions that were required during this pre-emergency phase. Among the decisions were those to evaluate risks, threats and vulnerabilities to the facilities, justify evacuation or sheltering-in-place. Decisions were reexamined for each iteration of the sync matrix, and response operations adjusted accordingly.

Results: The HEOC staffs that used the sync matrix as the bases for making response decisions prior to the approach of Hurricane Earl and landfall of Tropical Strom Irene provided positive feedback regarding the value of the information presented in the tool. The sync matrix facilitated the sharing of information among decision-makers, response personnel, and hospital staffs. The use of temporal information, as the storms approached the shorelines, was valuable in identifying response priorities.

Conclusions: The sync matrix has proven very useful in providing accurate and concise information to inform the decision-making process for weather-related events. We continue to develop and adapt the sync matrix for use in other natural and man-made disasters. This requires constant socialization of this tool to ensure the most practical information is presented to the key decision-makers.

\section{S2-09-03: Decision-Making Process of Hospital Evacuation During Emergencies: The Safe Way or the Leader's Way?}

Bruria Adini, Ben-Gurion University of the Negev (Israel); Daniel Laor, Ministry of Health (Israel); Robert Cohen, Ben-Gurion University of the Negev (Israel); Avi Israeli, Hadassah Hebrew University (Israel)

Background: Not infrequently hospitals had to be evacuated as a result of disasters. This study presents elements that need to be considered when confronted with the possibility of evacuating a hospital.

Methods: There are four major alternatives to hospital evacuation: early discharge of patients; internal relocation; evacuation of patients while leaving staff on alert to admit additional patients, and; full evacuation of patients and staff to other facilities.

Results: The evacuation process significantly impacts on the surrounding community. When a hospital is at risk, the easiest position for the hospital leadership is to evacuate the facility to safeguard the well-being of patients and staff. This decision will probably not be overly criticized, as safety of patients is considered justified. Nevertheless, a wider spectrum of considerations should be adopted. Influence of evacuation on patients, staff, family members, the community and the nation as well as repercussions to potential patients should be integral components of the decision-making process, parallel to risk assessment.

Conclusions: Policy makers should consider the following in the decision-making process: 1) has a directive for an evacuation of the population or other facilities that operate in the vicinity been issued? 2) To what degree is the distance between the facilities involved in the evacuation important? 3) To what degree is the absorbing facility capable of admitting and treating the evacuated patients? 4) What will be the outcome for provision of medical services to potential patients, and impact on the national resilience? 5) What are the information needs of the population in the region? 6) What type of information will strengthen effective behavior, and what is likely to cause anxiety? Decision to evacuate a hospital should not be made independently by the facility's administration; senior regional or national level officials acquainted with the broad situation. 


\section{S2-09-04: Seismic Vulnerability and Disaster Preparedness of Health Facilities: Comparing Predicted Performance with} Observed Evidence Following the February 22 Christchurch Earthquake in New Zealand

Jason McIntosh, University of Canterbury (New Zealand); Sonia Giovinazzi, University of Canterbury (New Zealand); Thomas Kirsch, Johns Hopkins University (United States); Judith Mitrani-Reiser, Johns Hopkins University (New Zealand); Tom Wilson, University of Canterbury (New Zealand); Caitlin Jacques, Johns Hopkins University (United States)

A magnitude 6.2 earthquake struck the city of Christchurch at 12:51pm on February 22, 2011. The earthquake caused 186 fatalities, a large number of injuries, and resulted in widespread damage to the built environment, including significant disruption to lifeline networks and health care facilities. Critical facilities, such as public and private hospitals, government and private emergency services, physicians' offices, clinics and others were severely impacted by this seismic event.

This paper presents the physical and functional impact of the February 22 Christchurch earthquake on the regional public healthcare system by analyzing how it adapted to respond to the emergency and continued to provide health services. Firstly we assess the seismic performance of the facilities, mechanical and medical equipment, building contents, internal services and backup resources. Secondly we investigate the reduction of functionality for clinical and non-clinical services, induced by the structural and non-structural damage. Thirdly we assess the impact on single facilities and the redundancy of the health system as a whole following damage to the road, power, water, and wastewater networks. Finally, we assess the healthcare network's ability to operate under reduced and surged conditions. The effectiveness of a variety of seismic vulnerability preparedness and reduction methods is critically reviewed by comparing the observed performances with the predicted outcomes of the seismic vulnerability models.

The results show non-structural damage to utilities and suspended ceilings were far more disruptive to the provision of healthcare than the minor structural damage to buildings. The physical damage to the healthcare network has reduced capacity and further strained a health care system already under pressure. However, the Canterbury healthcare system has exhibited high adaptive capacity, the strong integration with the wider New Zealand healthcare system has meant a high standard of healthcare continues for the Canterbury region.

S2-09-05: The Impact of Structural and Non-structural Damage on Healthcare System Functions Following the Christchurch Earthquake

Thomas Kirsch, Johns Hopkins University (United States); Sonia Giovinazzi, University of Canterbury (New Zealand); Judith MitraniReiser, Johns Hopkins University (New Zealand); Jason McIntosh, University of Canterbury (New Zealand); Tom Wilson, University of Canterbury (New Zealand); Caitlin Jacques, Johns Hopkins University (United States)

Background: On February 22, 2011 a M6.3 earthquake struck Christchurch, New Zealand causing 185 fatalities, 8,600 injuries, major damage to infrastructure systems, and affected the entire healthcare system.

Methods: A system-wide assessment of the impact, response and recovery of the healthcare system was undertaken. Damage identified by engineering surveys was matched to loss of healthcare facility capacity and services, using surveys of hospital managers and those from the Earthquake Engineering Research Institute. Critical infrastructure (power, water, sewer, communications), hospital services (emergency, surgery, in- and outpatient), clinical support services (laboratory, radiology, medical gases, medical records), and support services (food, laundry, staffing) were assessed.

Results: Twelve non-psychiatric healthcare facilities were surveyed, 4 in Christchurch city. Three sustained significant damage, with one closing for 2 months. The main hospital and only trauma center sustained structural and non-structural damage, as well as loss of utilities that strained their ability to function and led to widespread spontaneous and organized evacuation and the closing of some structures. Key clinical support services such as lab and radiology recovered within hours. Functions such as food, laundry and medical records were affected. Power loss was identified as the main impediment to care by all facilities. The loss of sewers and closing of, long-term care facilities was the greatest strain on the entire system. Rapid coordination between facilities facilitated emergency response. Local transfers to a geriatric hospital and distant transport of patients and long-term care residents by the national government provided surge capacity.

Conclusions: Non-structural facility damage was more disruptive than structural damage in delivering healthcare services. The loss of municipal power was most critical in the emergency phase but long-term care facilities vulnerabilities and sewer disruptions were the greatest problems after 48 hours. Local and national coordination improved the system-wide response. 


\title{
S2-10 Coordination of Disaster Responses Free Papers
}

\section{October 16, 2012 4:00-5:00}

\author{
S2-10-01: Lessons Learned from a Mass Casualty Full Scale Exercise with 560 Casualties
}

Mario Di Gennaro, German Red Cross Frankfurt am Main (Germany); Leo Latasch, German Red Cross Frankfurt am Main (Germany)

Background: In the framework of a national research project called SOGRO, funded by the German government, we run a full scale exercise with 560 "casualties" on Frankfurt airport. The goal was the evaluation of medical disaster management supported by electronic triage.

Methods: The exercise was run in real time. According to triage category, the proportional distribution of the 550 casualties was 100 red, 150 yellow and 300 green. All patients from the triage category red and yellow were transferred to the 16 hospitals in Frankfurt. No medical treatment was initiated inside the hospitals. Once the patients reached the hospital, the triage results from the field were compared to the electronic results send in long time before the patient reached the hospital. At the scene of the accident, main goal was to get a complete overview as fast as possible and to transfer these data to dispatch center, hospitals, fire brigade, health authorities and police. Medical treatment according to the attached status was not deemed as necessary, triage was done by 15 paramedics equipped with a PDA and RFID wristbands.

Results: The electronic triage shortened the triage time, so that it took only $37 \mathrm{~min}$. to get a complete overview of the scene. The first patient category red was transported after 42 min.; 2.5 hours after the start all 250 patients (red and yellow) had reached the hospitals. Because of the enormous amount of patients arriving at the evacuation area, it was very difficult to stay on top at all time. Conclusion: Electronic triaging is absolutely capable of shortening the triage time and if done correctly reduces mistakes in choosing the right triage category. Hosted on the internet all "players" receive necessary and updated information in a very early state which has not been the case before.

\section{S2-10-02: Social Media as a Tool for Hospital Incident Command}

Jack Manzella, Resurrection Health Care (United States)

Background: One of the main challenges in Hospital Command is knowledge of what is happening at the scene, as well as what is happening at other hospitals. Having this knowledge allows hospitals to better prepare for what may present to their Emergency Rooms. In today's world of social media, those answers are at your fingertips, you just need to know where to look!

Methods: This presentation will show participants how Chicago has developed its own private social network among emergency preparedness contacts, as well as how to use social media such as Facebook, twitter, Tweetdeck, ustream and livestream to collect on the scene intelligence directly from the site. Specific references to Chicago's NATO summit will be used.

Results: Hospitals are able to know the exact location of incidents, plans and comments from those directly on the scene, and other information that assists them in their response.

Conclusion: Social Media can be used as a communications tool internally between hospitals and public health, and can also be used as a tool for the collection of intelligence from the scene. All external information presented will be for FREE publicly accessible information.

\section{S2-10-03: Disaster-Relief Trainings to Achieve the Coordination of Rescue and Medical Teams}

Tomoko Yamashita, Saga University, Emergency And Critical Care Medicine (Japan); Hideyuki Kusaba, Commander, Fleet Activities Sasebo Japan (Japan); Fumio Kamogawa, Sasebo Fire Department (Japan); Kazuyuki Yamazumi, National Hospital Organization Ureshino Medical Center (Japan); Hayato Takayama, National Hospital Organization Nagasaki Medical Center (Japan)

Background: In Japan, We have developed and dispersed the educational course of Disaster Medical Assistance Team (DMAT) since 2005. But it is not widely known among rescue workers about the role of medical teams at the time of a disaster. It is also distant for medical staffs to coordinate rescue teams, because most of they don't work with rescue workers in their daily tasks. We have felt a need of practical trainings or drills to achieve the coordination of rescue and medical teams.

Methods: We held a disaster-relief training workshop on June 13, 2010, in Nagasaki prefecture. Prior to start the drill, we gave two lectures about the role of a medical team in a rescue site and the basic knowledge of rescue skills. The drill was organized for 1.5 hours, using a house which was condemned to demolition. The scenario was secret for participants. Before and after the workshop, we had a questionnaire survey for attitude changes about a collaborative work between a rescue team and a medical team.

Results: 90 people participated in the workshop (43 rescue workers, 17 ambulance workers, 13 paramedics, 17 medical staffs). At first, rescue workers tended to downplay the importance about the division of roles or the establishment of command and control 
system between rescue teams and medical teams, but their attitude changed after the drill $(\mathrm{p}<0.05)$. They also understood the need to know about basic trauma survey skills and some medical terms.
Conclusions: To achieve mutual understanding, it is important to have drills both rescue teams and medical teams participate. We will report including some bibliographic consideration.

\section{S2-1 1 Children in Disasters Free Papers October 16, 2012 11:15-12:30}

\section{S2-11-01: Specialized Surgical Care to Children with Open Injuries Suffered in Earthquakes by Multidisciplinary Pediatric Team}

Pavel Medinskiy, Clinical and Research Institute of Children's Surgery and Trauma, Moscow (Russian Federation); Valery Mitish, Clinical and Research Institute of Children's Surgery and Trauma (Russian Federation); Leonid Roshal, Clinical and Research Institute of Children's Surgery and Trauma (Russian Federation)

Background: This study demonstrates the effectiveness of the surgical treatment for open injuries of soft tissues and bones that are complicated by infection in children suffered in earthquakes by applying primary and early reconstructive or plastic surgery. Methods: This study is based on the treatment of 197 children suffering in earthquakes in Pakistan (2005), Indonesia (2006, 2009), and Haiti (2010). The children were admitted to the organized centers to provide specialized surgical care. These centers were established at local hospitals by a multidisciplinary pediatric team. Open fractures were $21.0 \%$, wounds were $55.6 \%$, deep infection of the amputation stump was $11.4 \%$ and crush syndrome were $12.0 \%$. Results: Mistakes typical for the first stage (before specialized surgical care) of surgical treatment have been outlined: (1) refusal to make a debridement, (2) performing semi-closed fasciotomy without lesion focus revision, (3) putting primary sutures on the crashed tissues, (4) finishing the surgery of extremity amputation with the primary stump formation, (5) performing internal osteosynthesis under surgical infection. Steps on specialized surgical care stage included: (1) radical wound debridement; (2) intensive therapy; (3) extracorporal detoxication; (4) wound treatment with multicomponent ointments with polyethyleneglycol base; (5) external osteosynthesis (include Ilizarov method); and (6) early reconstructive and plastic surgeries (skin grafting $-22.4 \%$,plastics with local tissues - 77.6\%). Healing with primary intension was seen in $90.3 \%$ cases. All damaged limbs planned to amputations early were saved. All the children with open fractures gave satisfactory results.

Conclusions: Complex surgical treatment of open injuries of soft tissues and bones in child victims of earthquakes must be conducted by pediatric multifunctional teams at hospitals. Primary and early reconstructive and plastic surgeries minimize the rate of disability and restore anatomical and functional integrity of the damaged body parts.

\section{S2-11-02: Pediatric Orthopedic Injuries Following an Earthquake}

Elhanan Bar-On, Schneider Children's Medical Center, Israel Defense Forces Medical Corps, Tel Aviv University-Sackler Medical School (Israel); Ehud Lebel, Shaare Zedek Medical Center and Israel Defense Forces Medical Corps (Israel); Nehamia Blumberg, Tel Aviv Souraski Medical Center and Israel Defense Forces Medical Corps (Israel); Rami Sagi, Tel Aviv Souraski Medical Center and Israel Defense Forces Medical Corps (Israel); Yitshak Kreiss, Israel Defense Forces Medical Corps (Israel) Pediatric Orthopedic Injuries Following an Earthquake: Experience in an Acute Phase Field Hospital Elhanan Bar-On MD MPH, Ehud Lebel MD, Nehemia Blumberg, Rami Sagi MD, Yitzhak Kreiss MD,MPH, Israel Defense Forces Medical Corps

Background: Following the 2010 earthquake in Haiti the Israel Defense Forces Medical Corps deployed a field hospital in Port au Prince. The purpose of this study was to characterize the injuries sustained by the pediatric population treated in the hospital and examine the implications for planning deployment in future similar disasters.

Methods: Medical records of children treated in the hospital were reviewed and compared to the adult population.

Results: 1,111 patients were treated at the hospital. 37\% were aged 0-18 yrs. Earthquake related injuries were the cause of admission in $47 \%$ of children and $66 \%$ of adults. $47 \%$ of children with traumatic injuries sustained fractures. $72 \%$ were in the lower limbs, $19 \%$ in the upper limbs and $9 \%$ in the axial skeleton with the femur being the most common long bone fractured. There were four functional operating theatres and treatment guidelines were adjusted to the rapidly changing situation. Soft tissue injuries were treated by aggressive debridement. Fractures were stabilized by external fixation or casting. Amputation was performed only for nonviable limbs or life threatening sepsis. In order to maximize hospital surge capacity, minor procedures were performed in the wards under sedation and patients were discharged after an average of 1.4 days with subsequent follow-up in clinic.

Conclusion: Children constitute a high percentage of patients in a developing country. The epidemiology of pediatric injuries following an earthquake differs significantly from that encountered in everyday practice and compared to adults. Children sustain a significantly higher percentage of femoral fractures and are more likely to require surgery. 


\title{
S3-06 Competencies of Workers and Accountability Free Papers
} October 17, 2012 11:00-12:00

\author{
S3-06-01: Are We Successful in Preparing Hospitals for Pandemic Influenza?
}

Bruria Adini, Ben-Gurion University of the Negev (Israel); Daniel Laor, Ministry of Health (Israel); Limor Aharonson Daniel, Ben-Gurion University of the Negev (Israel)

Background: Studying the effectiveness of various interventions is essential to prioritize the most efficient means to prepare for pandemics.

Objectives: To examine hospital managers' perception of measures implemented to facilitate preparedness for pandemic influenza, and assessment of readiness and capability to manage the pandemic.

Methods: A national pandemic preparedness program was implemented in 2009 by the Ministry of Health (MOH). The program consisted of various components including equipment; conferences; guidelines; training \& drills; and evaluation of preparedness. A survey was conducted among hospital managers to assess their perception of the program's effectiveness as well as preparedness for the pandemic and capacity to manage it.

Results: $82 \%$ responded to the survey. $91 \%$ and $87 \%$ (respectively) of the hospitals rated themselves as highly or very highly prepared and capable for dealing with pandemics. High correlations were found between hospital managers' assessment of preparedness and capacity to manage the pandemic (rho $=$ $0.761, p=.000$ ). Preparedness for pandemic flu highly correlated with familiarity with the disease (rho $=0.605, \mathrm{p}=.003$ ); evaluations of preparedness (rho $=0.627, \mathrm{p}=.001)$; and conferences $(\mathrm{rho}=0.673, \mathrm{p}=.001$ ). Documents issued by the $\mathrm{MOH}$ accounted for $35 \%$ of the variance regarding perception of capability (Adjusted $\mathrm{R} 2=.346, \mathrm{p}=.002$ ). Including evaluations of preparedness resulted in an additional $15 \%$ of the variance being explained $(\mathrm{R} 2$ change $=.146, \mathrm{p}=.026)$. Using the stepwise method, a significant model explains $47.3 \%$ of the variance (Adjusted $\mathrm{R} 2=.473$ ).

Conclusions: Familiarity with disease, guidelines disseminated by $\mathrm{MOH}$ and evaluation of preparedness impact on perceived preparedness and capability to manage pandemic influenza. There is a need to expand the research to identify additional measures which are perceived by field managers as potentially effective in raising emergency preparedness for future pandemics.

\section{S3-06-02: BGU Emergency Response Volunteering Initiative-A University-City Partnership}

Limor Aharonson-Daniel, Ben-Gurion University of the Negev (Israel); Bruria Adini, Ben-Gurion University of the Negev (Israel); Avishay Goldberg, Ben-Gurion University of the Negev (Israel)

Background: When a disaster strikes, authorities are often overwhelmed and unable to provide the immediate needs of the population. Local residents may be forced to be the first responders. An innovative project of organizing and training a permanent ensemble of skilled volunteers from the university has been established at Ben-Gurion University of the Negev. The volunteers will be adept to assist in bridging gaps until local authorities have regained their capacity.

Methods: Students and staff were approached by email, enquiring about their skills and willingness to volunteer in the community when crisis strikes. A list of anticipated tasks (such as operating childcare for essential workers or staffing information centers) was generated and offered to volunteers for the selection of their preferred volunteering area. Questionnaires were online and results accumulated immediately in the volunteering control room facilitating immediate analysis of available resources, contact and assignment.
Results: 3356 people completed the survey. More than 1,000 of them were willing to volunteer. Past education and abilities were considered in matching between volunteer skills and interest and the tasks listed as required. Specific basic training has been provided by the Homefront command that has partnered this initiative. The city is now providing more specific in-depth training to team heads. Particular attention is given to weak populations and those with special needs. In future national, municipal and university preparedness drills, these volunteers will be incorporated in their emergency roles.

Conclusion: Beyond the obvious contribution to the city's ability to respond, past experience suggests that people with a task or a responsibility tend to handle crisis situations better. It is therefore anticipated that the volunteering project will contribute not only to the community surrounding $\mathrm{BGU}$ but also to the volunteers themselves. 